\title{
Study on Optimization of Port Railway Transportation Mode
}

\author{
Liu Donghui ${ }^{1, a^{*}}$, Yu Zhouming ${ }^{2, b}$, Jiang Minghui ${ }^{3, \mathrm{c}}$, Fan Runze $^{4, \mathrm{~d}}$,Wang Xiulei ${ }^{5, \mathrm{e}}$,Wang Zengjin ${ }^{6, \mathrm{f}}$ and Lu Hongli ${ }^{7, \mathrm{~g}}$ \\ ${ }^{1}$ Logistics Engineering Department, ${ }^{2}$ Traffic Engineering Department, ${ }^{3}$ Traffic Equipmenting and Control Engineering Department, \\ ${ }^{4}$ Traffic Engineering Department, ${ }^{5}$ Safety Engineering Department, ${ }^{6}$ Logistics Engineering Department, ${ }^{7}$ Safety Engineering Department, \\ Shandong Jiaotong University, Jinan Shandong Province, 250357, China
}

\begin{abstract}
With the continuous development of port economy and the continuous promotion of industrial transformation and upgrading in China, the mode of gathering and distributing transportation in port area has gradually become the core factor to enhance the competitiveness of the whole logistics chain of port. It always play an important role in the port collection and distribution system. Especially for inland economic hinterland ports, it is of great significance to develop railway transportation and optimize port railway collection and distribution system. Based on the development and application of the theory of port railway transportation at home and abroad, this paper briefly analyzes the present situation and trend of port railway transportation mode. Combined with the demand characteristics of the current port railway transportation system and the problems that need to be further improved after the reform of freight organization, the form and task of optimizing the port railway transportation mode are clarified.
\end{abstract}

\section{Introduction}

Economic globalization has promoted the rapid development of international trade, and international trade continues to grow and strengthens the service size of the international logistics industry. The port as an important node of the international logistics industry, becomes more prominent in international trade. However, there are many international domestic ports, and each other is intertwined with each other, and the port competition is continuously intensified. The competitive situation is continuously upgraded, and the competitive relationship between the traditional points and points between ports has gradually been replaced by the overall logistics chain relationship of the port. Competition of the logistics chain The key factor in the port is the harbor co-transportation system. The system consists of railways, roads, water transport, pipelines, aviation and corresponding transportation hubs, which are connected to the hinterland of ports and ports. Vigorously developing the railway to engage in the network is conducive to promoting the future development of China's port, and is also an important development direction of China's future optimization of port collection mode. The port collection system is connected to the port, providing a transportation system for the centralized and evacuation services of port throughput goods. Its collection of ribbons consists of integrating machine, loading and unloading line, transportation organizational system, and human resources system. The goods are imported from all over the country to the concentration of goods, and it is called the evacuation or transportation of goods. Equivalent capacity is the core of port through the

* Corresponding author: 2289721243@qq.com

841272082@qq.com

2863479935@qq.com ability, including waterways, land, empty roads, and underground, transportation methods mainly include ship transportation, railway transportation, road transport, pipeline transportation and aviation transport.

\section{Analysis of problems in the current port rail sets.}

\subsection{Top-level information communication decision lack big data support.}

At present, the relevant parties involved in the port and railway transportation mode include port, freight forwarder, customs and railway. The Quartet hopes to obtain the big data information of all parties to facilitate the optimization of decision-making. However, in practice, due to the existence of information confidentiality and rights barriers, the basic information of big data is in the form of information island, and most of the time of daily transportation production decision is occupied by understanding and communicating information. The actual communication information not only lags behind, but also can not objectively reflect the actual situation of the demand for collection and transportation, so it can not serve the decision-making of efficient collection and transportation production.

\subsection{Collecting the main related parties lack global awareness.}

In the daily operation mode of port loading and unloading, 
due to the proportion of railway episodes, it is generally difficult to form an advantage with highway and ship transportation volume, and the port loading and unloading company's attention is not high, especially in the acquisition. In the case of the lack of effective channel information, the use of the lack of scientific planning in front and rear yards before and after the port, and the characteristics of the collection of salient goods, the retransmission of the transportation and railway vehicles and railway vehicles, the railway port The production time of collecting sports is increasing, and the efficiency of the collection is difficult to improve.

\subsection{Road enterprise rules and regulations and operation methods are not integrated.}

The port railway integration system and the front system in Hong Kong and the Hong Kong system are different from the management subject. The rules and regulations are also different. After many years of safety management standardized construction, the Hong Kong front railway has been greatly improved, and the operation standard implementation and safety protection is standardized. The railway in Hong Kong is often more emphasis on the operation due to supervision and inspection and the internal attention of the port. Efficiency, this is an objectively caused the railway transport rules and operational methods of railway transportation rules and operation methods in road transport.

\section{3 harbor integration system demand analysis on rail transport mode.}

The port collection system is constantly changing, and the port railway integration system also needs to be equipped with upgrades. Summarizing the demand for railway integration services on railway sets of transportation systems in major ports, basically.

\subsection{Composition of Port Railway Set Broadcasting System.}

The port railway integration system is connected to the port. The transportation system for the concentrated and evacuation services of the transportation of the transportation in the port is usually composed of port areas, Hong Kong former rail transport equipment, handling equipment, etc., and three Inspection, freight forwarding, loading and unloading companies, rail transport enterprises, etc. The internal structure is shown in Figure 1 .

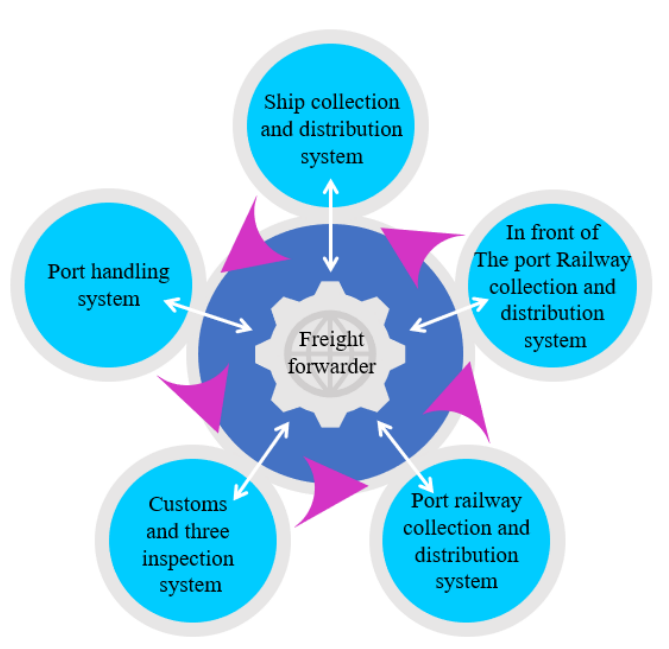

Fig. 1. port railway collection and distribution structure chart

\subsection{Port Railway Set Broadcasting System Planning and Port Planning Coordination.}

The port plan must first consider the combination of the co-transportation, and fully demonstrate the feasibility and necessity of railway ports. After the introduction of the feasibility and necessary problems, the port is invested in the railway, and the port railway integration system planning must analyze the amount of freight flow rate suitable for railway transportation in the port of the port. Overall planning is performed. The specific process of planning is shown in Figure 2.

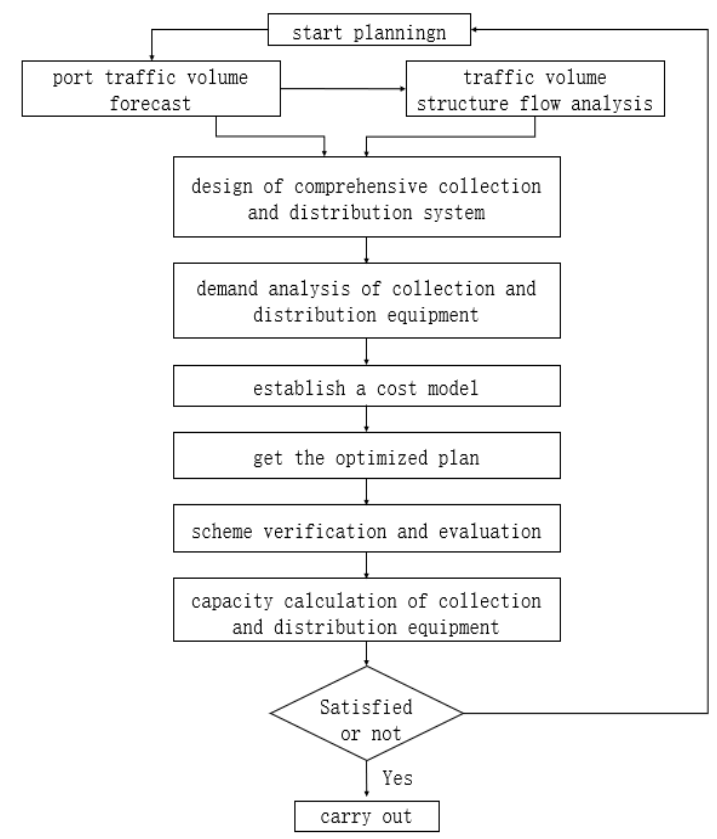

Fig. 2. Planning Process of port railway transportation system

\subsection{Dynamic sharing of collection and distribution information.}

Because the railway is a large, orderly, flexible and dynamic system, it is itself divided into various 
departments such as vehicles, machinery, engineering, and electricity. Only when these departments cooperate, the railway transportation system can operate normally. Therefore, information between departments must be quickly transmitted and shared information resources can be achieved in order to make all units work in unison and ensure the safety, punctuality and continuous operation of trains. On the other hand, the port railway collection and distribution system, as a linking system between the production organizations of the road and port, must include the dynamic information of railway traffic flow to realize the real-time transmission of the dynamic traffic flow, route, and personnel organization of the railway system. For the Hong Kong Railway This information is also a long-standing hope that the port can automatically obtain the necessary information to strengthen the organization of collection and distribution in the port and reduce the problems of the joint.

\section{Optimization of collection and distribution modes in port and railway areas.}

The optimization of the collection and distribution mode of the port and railway area includes the ship subsystem, the loading and unloading subsystem, the construction subsystem, and the freight subsystem in the port collection and distribution system. The following figure 3 is the optimized port and railway collection and distribution vehicle flow diagram Figure 4 is an optimized production organization system diagram of the collection and distribution system. It can be seen from the figure that the optimization of the collection and distribution system requires adjustments to the existing collaboration methods of various types of work, and also needs to break the traditional division of labor to achieve scheduling. Concentration and information sharing, the following article will focus on several aspects of the optimization of collection and distribution.

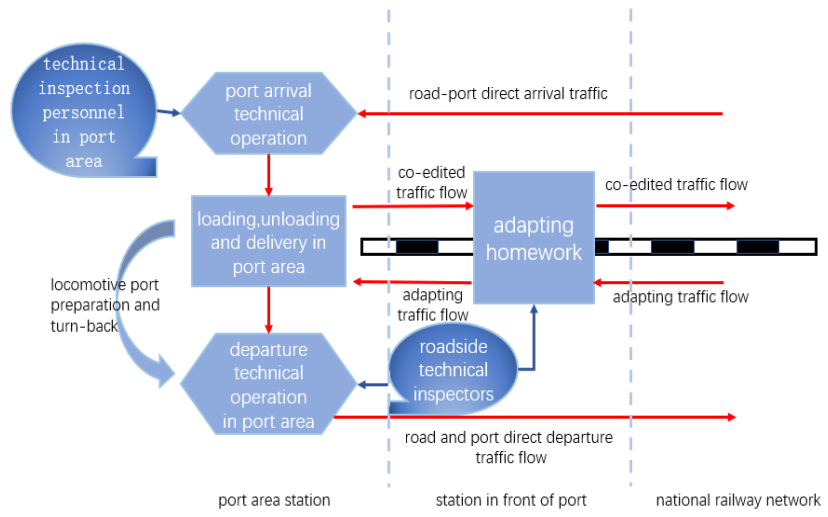

Fig. 3. optimized collection and distribution traffic map in port railway area

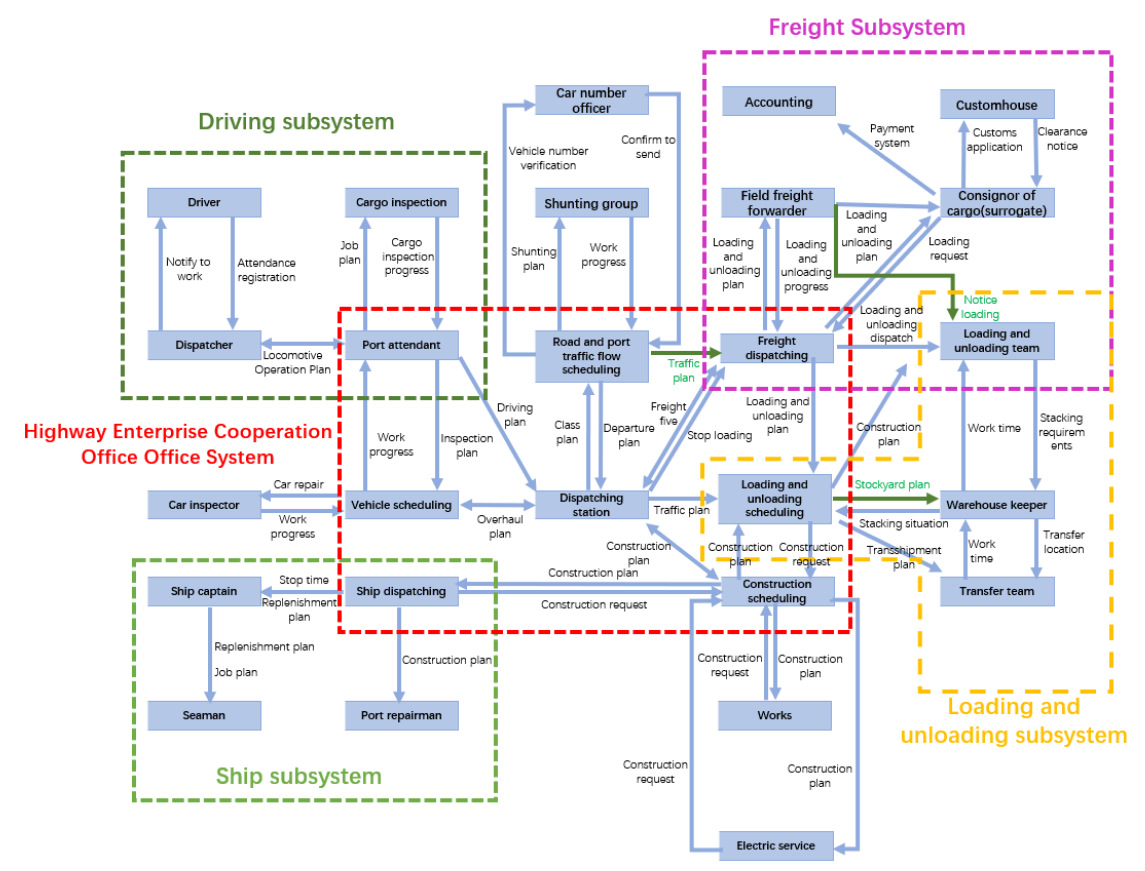

Fig. 4. optimized production and organization chart of port transportation

\subsection{Activating the vitality of the freight forwarding market.}

(1) Increase government supervision of the freight forwarding market and create a good competitive atmosphere for competitive enterprises. The government has intensified anti-monopoly investigations on the freight forwarding market, especially the regional freight forwarding market, strengthened the management of freight forwarding companies, standardized the competition mechanism of the freight forwarding market, and cultivated a reasonable scale of the regional freight forwarding market.

(2) For the transportation of long-term bulk materials, a bidding system for freight forwarders will be implemented to increase the vitality of the freight forwarding market, pave the way for reducing overall 
logistics costs, and increase the sensitivity of freight forwarding market adjustments.

(3) Increase port information transparency, connect "information islands" such as customs, port areas, storage yards, and shipping companies, and publish them in a timely manner, so that all forwarders can obtain and use port freight information in a timely manner.

(4) Intensify investigations into unspoken rules of the freight forwarding industry, crack down on corruption and unfair competition in the freight forwarding market such as false bids and setting rebates, and establish a good industry atmosphere.

(5) Establish a supporting financial product system for the freight forwarding industry, improve the level of market competition, increase integration with large multinational freight forwarding companies, and guide the healthy development of the freight forwarding market.

\subsection{Implementation of the Office of the Road Enterprise Cooperation Agency.}

The steps are shown in Figure 5. The implementation of the Office of the Road Enterprise Cooperation Agency is not only a requirement for railways to tap potential and improve efficiency, reform and innovation, but also an important way for enterprises to reduce transportation costs, accelerate cargo turnover, and achieve transportation growth. The implementation steps include the following step:

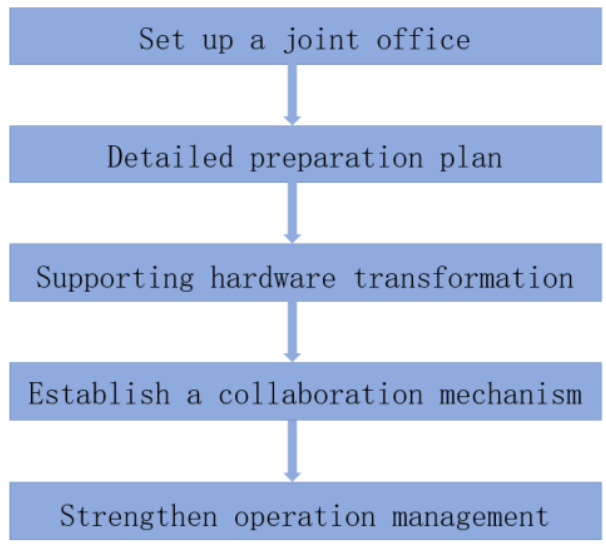

Fig.5. steps of enterprise offices operating procedures

\section{Conclusion.}

(1) In the process of optimizing the collection and distribution mode of port and railway, the transportation volume should be forecasted in advance according to the change trend of the transportation volume. Through the comparison and analysis of the expected capacity of the transportation volume and the actual capacity of the existing equipment, it is necessary to find whether the existing equipment has a capacity bottleneck and judge. Which equipment needs to be expanded and transformed to achieve the goal of dynamically matching the collection and distribution capacity with the transportation volume.

(2) The optimized adaptability model of the port and railway collection and distribution capacity is that the passage capacity of the railway in front of the port is greater than the capacity of the railway in the port area than the required capacity of the port collection and distribution volume. Among them, the port traffic demand throughput capacity is obtained by converting the port traffic volume. In the actual calculation, the value of the cargo flow fluctuation coefficient should be appropriately large, so as to ensure that the calculated demand capacity maximizes the freight flow under adverse conditions of spot flow fluctuations. Energy demand, to reach the goal of overall coordination of the collection and distribution capacity of the port and railway areas.

(3) The optimization of port and railway collection and distribution mode includes two aspects: integration of transportation production system and adjustment of management mode. The integration of the transportation production system requires adjustments to the existing traditional division of labor and cooperation modes of various types of work, so as to realize the centralized dispatch and unified command of the collection and distribution of the port and railway areas.

\section{References}

1. Research on Evaluation Index and Calculation Method of Container Collection and Distribution Structure of Coastal Port[J]. Zhu Jishuang. Comprehensive Transportation. 2020(08)

2. Coordination analysis of the development of my country's coastal port collection and transportation system under the "One Belt and One Road" initiative [J]. Li Shuang, Yue Ming, Lu Jiajing, Huang Fu Yu Zhen. China Water Transport (second half of the month). 2019(06)

3. Research on optimization of collection and distribution system of Huanghua Port [D]. Zhen Linzhi. Lanzhou Jiaotong University. 2020

4. Research on the problems and countermeasures of railway transportation channels in the ports around Bohai Sea [J]. Meng Xinxin, Wang Xiuhua, Zou Weiqiang. Railway Survey. 2019(03)

5. Research on the Coordination Evaluation of the Railway Collection and Distribution System in Caofeidian Port Area [D]. Wu Liuyi. Beijing Jiaotong University. 2018

6. Analysis of the development status of my country's port collection and distribution system [J]. Chen Yu. China Ports. 2017(03)

7. Geng Yanbin, Cui Yuan, Sun Xiangjun, et al. Problems and suggestions [J] Comprehensive Transportation, 2016(1): 18-23.

8. Geng Yanbin. The overall understanding and construction focus of my country's Jishugang Railway[J]. Railway Transportation Economy, 2015(6): 20-23.

9. Major ports in the world [J]. Wang Zheng. China Ocean Shipping. 2016(04) 